\title{
Gender Differences in the Monthly Variation in Throwing Distances among Children Using Different Balls
}

\author{
Hiroshi Yamanaka1, Hiroki Aoki2*, Shobu Sato' ${ }^{1}$, Hiroe Sugimoto ${ }^{1}$ \\ ${ }^{1}$ Shiga Junior College, Shiga, Japan \\ ${ }^{2}$ National Institute of Technology, Fukui College, Fukui, Japan \\ Email: *aoki@fukui-nct.ac.jp
}

How to cite this paper: Yamanaka, H., Aoki, H., Sato, S., \& Sugimoto, H. (2018). Gender Differences in the Monthly Variation in Throwing Distances among Children Using Different Balls. Advances in Physical Education, 8, 151-156.

https://doi.org/10.4236/ape.2018.81014

Received: October 29, 2017

Accepted: February 25, 2018

Published: February 28, 2018

Copyright $\odot 2018$ by authors and Scientific Research Publishing Inc. This work is licensed under the Creative Commons Attribution International License (CC BY 4.0).

http://creativecommons.org/licenses/by/4.0/

\begin{abstract}
The objective of this study was to consider the gender differences in the monthly variation in throwing distances among kindergarten children using different balls. The subjects of this study were 111 healthy males and 109 healthy females. The subjects' throwing distances of softballs and tennis balls were measured in June and November. By a gender-based two-way analysis of variance (difference by ball type $x$ difference by month), we observed that the throwing distance of softballs was less than that of tennis balls for both males and females. Moreover, we note that the throwing distance of both ball types was shorter in June than in November. A second two-way analysis of variance (difference by gender $\times$ difference by ball type) determined that the throwing distance variation ratio $(($ November/June $) \times 100)$ was greater for softballs than for tennis balls among females only; however, this difference was not significant. The above results show that the throwing distance of softballs is less than that of tennis balls. However, we observe that the selection of ball type has no major effect on the monthly variation in throwing distances among children and that the trend does not vary greatly between males and females.
\end{abstract}

\section{Keywords}

Kindergarten Children, Softballs, Tennis Balls

\section{Introduction}

The throwing distances of balls and flying discs are often measured to evaluate children's throwing abilities (Murase et al., 2002; Sugihara et al., 2006; Zhou et al., 2014; Sedlak et al., 2015). In Japan, softballs (size 1) or tennis balls are normally 
used for this purpose (Fuji et al., 2006; Ikeda \& Aoyagi, 2009). However, softballs, which have a diameter of approximately $9 \mathrm{~cm}$, are more difficult for children with small fingers to grasp. Moreover, as tennis balls weigh approximately 50 $\mathrm{g}$ and softballs weigh approximately $150 \mathrm{~g}$, it is expected that children who are immature in terms of strength development and throwing actions will have difficulty when throwing a softball as compared to when throwing a tennis ball. Demura (1993) measured throwing distances among children and found that the throwing distance when using softballs was less than that with tennis balls, golf balls, etc.

A gender-based difference in throwing distances from infancy has been recognized, and it is clear that males have a shorter throwing distance than females (Ikeda \& Aoyagi, 2009). Gender differences in the development of throwing actions have been cited as the main cause of the difference in throwing distances, but it is possible that the gap in throwing distances of softballs and tennis balls, especially, increases with age among female children with immature throwing actions as compared with males. Both genders, of course, can throw a ball farther as they get older. However, males get closer to an adult throwing action as they grow, whereas many females have an immature throwing action even at the age of five (Demura, 1993). As already noted, immature throwing actions make it particularly difficult to acquire distance when throwing a softball. Therefore, it is possible that, among females, there will be less increase in the throwing distance of a softball than that of a tennis ball.

The objective of this study was to consider the gender differences in the monthly variation in throwing distances among children using different balls.

\section{Methods}

1) Subjects

The subjects were 111 healthy males and 109 healthy female kindergarten students. Permission was obtained from kindergarten principals and the students' guardians after the objectives, methods, and risks of the experiment were explained.

2) Measurement method

In June and November, the subjects' throwing distances of size 1 softballs (diameter: $8.5 \mathrm{~cm}$; weight: $141 \mathrm{~g}$ ) and tennis balls (diameter: $6.8 \mathrm{~cm}$; weight: 58.5 g) were measured. The throwing distances were measured twice, and the longer throw was taken as the representative value.

3) Method of analysis

A two-way analysis of variance (variation by ball type $\times$ variation by month) was conducted to consider the impact of these two factors. Moreover, to consider the variation of the throwing distance ratio by ball type ((half year after/half year before) $\times 100$ ), a two-way analysis of variance (gender difference $\times$ variation in ball type) taking into account only one factor was conducted. To consider the degree of variation, the effect size (ES) was calculated. Tukey's honest significant 
difference was used as the official multiple comparison test. The level of statistical significance was set at $5 \%$.

\section{Results}

Table 1 shows the variation in throwing distances by ball type and between the two testing periods among males. Significant main effects were found in the factors of difference by ball type and difference by month. Moreover, the throwing distance of softballs was less than that of tennis balls (ES: 0.39 - 0.42), and the distance in June was less than that in November (ES: 0.17 - 0.19).

Table 2 shows the variation in throwing distances by ball type and month among females. A significant mutual interaction was found from the two-way analysis of variance. The throwing distance of softballs was less than that of tennis balls as a result of the verified multiple comparison test (ES: $0.29-0.54$ ), and the distance in June was less than that in November (ES: 0.17 - 0.46).

Table 3 shows the variation in throwing distance ratios by gender and the difference by ball type. Significant effects were found only in the factor of variation by ball type for the two-way analysis of variance. The throwing distance of softballs was significantly greater than that of tennis balls only among females (ES: 0.10 - 0.36) for the verified multiple comparison test.

Table 1. Basic statistics and average value differences for throwing distances by ball type and month among males.

\begin{tabular}{|c|c|c|c|c|c|c|c|}
\hline & \multicolumn{2}{|c|}{ June } & \multicolumn{2}{|c|}{ November } & \multirow{2}{*}{\multicolumn{2}{|c|}{ F-value }} & \multirow[b]{2}{*}{ Post-hoc } \\
\hline & Mean & SD & Mean & SD & & & \\
\hline Softballs & 6.4 & 2.9 & 6.8 & 2.9 & $\mathrm{~F} 1: 12.15^{\star}$ & $\mathrm{F} 2: 112.77^{\star} \mathrm{F} 3: 0.60$ & $\begin{array}{c}\text { June: Softballs }<\text { Tennis } \\
\text { balls; Softballs: } \\
\text { June }<\text { November }\end{array}$ \\
\hline $\begin{array}{c}\text { Tennis } \\
\text { balls }\end{array}$ & 7.5 & 3.2 & 8.2 & 3.5 & & & $\begin{array}{c}\text { November: } \\
\text { Softballs < Tennis balls; } \\
\text { Tennis balls: } \\
\text { June < November }\end{array}$ \\
\hline
\end{tabular}

${ }^{\star} p<0.05$, Unit: $\mathrm{m}$.

Table 2. Basic statistics and average value differences for throwing distances by ball type and month among females.

\begin{tabular}{|c|c|c|c|c|c|c|c|c|}
\hline & \multicolumn{2}{|c|}{ June } & \multicolumn{2}{|c|}{ November } & & \multirow{2}{*}{\multicolumn{2}{|c|}{ F-value }} & \multirow[b]{2}{*}{ Post-hoc } \\
\hline & Mean & SD & Mean & $\mathrm{SD}$ & & & & \\
\hline Softballs & 3.8 & 1.3 & 4.4 & 1.3 & $\mathrm{~F} 1: 17.20^{*}$ & F2: $51.44^{*}$ & F3: 5.29 & $\begin{array}{c}\text { June: Softballs }<\text { Tennis } \\
\text { balls; Softballs: } \\
\text { June }<\text { November }\end{array}$ \\
\hline $\begin{array}{c}\text { Tennis } \\
\text { balls }\end{array}$ & 4.6 & 1.5 & 4.9 & 1.7 & & & & $\begin{array}{c}\text { November: } \\
\text { Softballs < Tennis balls; } \\
\text { Tennis balls: } \\
\text { June < November }\end{array}$ \\
\hline
\end{tabular}

${ }^{\star} p<0.05$, Unit: $\mathrm{m}$. 
Table 3. Variation in throwing distance ratios by gender, and basic statistics and average value differences by ball type.

\begin{tabular}{|c|c|c|c|c|c|c|c|c|}
\hline & \multicolumn{2}{|c|}{ Softballs } & \multicolumn{2}{|c|}{ Tennis balls } & & & & \\
\hline & Mean & SD & Mean & SD & & F-value & & Post-hoc \\
\hline Males & 119.7 & 62.9 & 114.3 & 38.7 & F1: 0.05 & F2: 6.72 & F3: 1.42 & $\begin{array}{c}\text { Females: Softballs > } \\
\text { Tennis balls }\end{array}$ \\
\hline Females & 125.4 & 45.6 & 110.8 & 34.1 & & & & \\
\hline
\end{tabular}

${ }^{*} p<0.05$, Unit: $\%$.

\section{Discussion}

In both June and November, the throwing distance of softballs was less than that of tennis balls for both males and females, and the ES of females in June was moderate (0.54). The throwing distance is influenced by the size and weight of the ball. Moreover, if the ball cannot be grasped in one hand or is too heavy, it is clear that the throwing distance will be reduced, because the entire body cannot be used in the winding-up movement (Demura, 1993; Toyoshima \& Miyashita, 1973). Moreover, according to Morimoto et al. (2003), the initial velocity of the ball decreases when the ball is heavier. The weight of the softball used in this study was $141 \mathrm{~g}$, which is a heavy ball for a child. Therefore, it is difficult to wind up effectively with the entire body when throwing the softball, and this difficulty limits the initial velocity of the ball. Therefore, the throwing distance of a softball may be less than that of a lighter tennis ball.

However, although the throwing distance of the softball and the tennis ball among both males and females was greater in November than in June, the ES was below the halfway point $(0.17-0.46)$. Demura (1993) reported that the throwing distance of a tennis ball varies at each age among children of the age of 4.5 and above and children below the age of 4.5. In this study, throwing distances increased during the five months from June to November; however, the increase was not significant. The throwing action develops along with age, but not to a great extent in such a short period; this is the main reason why the throwing distances with either ball did not increase greatly.

There was no gender difference in the throwing distance variation ratio for either ball, and the ratio between softballs and tennis balls changed significantly only among females, although the ES was less than the halfway point (0.36). Males, in comparison to females, develop their throwing capabilities more quickly (Takamoto et al., 2003), and a difference between the genders has been recognized in terms of ball speed and throwing distance (Ikeda \& Aoyagi, 2009, Thomas et al., 2010). The throwing action of females with an immature throwing ability was greatly affected by the weight of the softball, as was particularly noticeable in the case of younger females. Due to the comparatively large variation in the throwing distance of tennis balls and softballs among females (ES: 0.54), the throwing distance of softballs greatly increased with age (i.e., between June and November). However, the lack of any major difference in the age-based 
variation in the throwing distance between tennis balls and softballs may be due to the lack of development in the throwing action among females. Moreover, the strength applied to the ball by one's hand varies according to the mass ratio between the hand and ball. For males and females, there was no great improvement in the ability to efficiently transmit strength to the ball when throwing a heavy ball over the short term (half a year), which may be the reason why there was no major improvement in the throwing distance of softballs and tennis balls despite an additional six months of age.

\section{Conclusion}

The throwing distance of softballs was less than that of tennis balls. However, the selection of ball type did not have a great effect on the change over time in the throwing distance among the participating kindergarten children, and this trend did not vary greatly between the genders.

\section{References}

Demura, S. (1993). Contribution of Physical Fitness and Throw Form to Ball-Throw Distance and the Sex Difference in Preschool Children. Japan Journal of Physical Education, Health and Sport Sciences, 37, 339-350. https://doi.org/10.5432/jipehss.KJ00003391898

Fuji, K., Akimaru, T., Hanai, T., \& Sakai, T. (2006). Confirmation Regarding Secular Trend in Growth and Development of Physique and Motor Fitness in Preschool Children: An Approach from Physical Maturation Rate. The Japanese Society of Physical Fitness and Sport Medicine, 55, 489-502. https://doi.org/10.7600/jspfsm.55.489

Ikeda, T., \& Aoyagi, O. (2009). Relationships between Gender Difference in Motor Performance and Age, Movement Skills and Physical Fitness among 3-to-6-Year-Old Japanese Children Based on Effect Size Calculated by Meta-Analysis. School Health, 5, 9-23.

Morimoto, Y., Ito, K., Shimada, K., Kawamura, T., Ae, M., \& Muraki, Y. (2003). The Influence of Increasing and Decreasing the Weight of Ball on Baseball Pitching and Immediate Effect as the Assisted and Resisted Training Method. The Japanese Journal of Sport Methodology, 16, 13-26.

Murase, T., Tosi, S. H., \& Gallahue, D. L. (2002) Age-Related Performance of Disc Throwing for Distance in Children Aged 5 to 8 Years. JEduc Health Sci, 48, 142-143.

Sedlak, P., Pařízková, J., Daniš, R., Dvořáková, H., \& Vignerová, J. (2015) Secular Changes of Adiposity and Motor Development in Czech Preschool Children: Lifestyle Changes in Fifty-Five Year Retrospective Study. BioMed Research International, 2015, Article ID: 823841. https://doi.org/10.1155/2015/823841

Sugihara, T., Kondo, M., Mori, S., \& Yoshida, I (2006) Chronological Change in Preschool Children's Motor Ability Development in Japan from the 1960s to the 2000s. International Journal of Sport and Health Science, 4, 49-56. https://doi.org/10.5432/ijshs.4.49

Takamoto, M., Dei, Y., \& Ogata, M. (2003) Development of Running, Jumping and Throwing Motion in Elementary School Children. Japanese Journal of Sport Education Studies, 23, 1-15. https://doi.org/10.7219/jjses.23.1

Thomas, J. R., Alderson, J. A., Thomas, K. T., Campbell, A. C., \& Elliott, B. C. (2010) Developmental Gender Differences for Overhand Throwing in Aboriginal Australian 
Children. Research Quarterly for Exercise and Sport, 81, 432-441.

https://doi.org/10.1080/02701367.2010.10599704

Toyoshima, S., \& Miyashita, M. (1973) Force-Velocity Relation in Throwing. Research Quarterly, 44, 86-95.

Zhou, Z., Ren, H., Yin, Z., Wang, L., \& Wang, K. (2014) A Policy-Driven Multifaceted Approach for Early Childhood Physical Fitness Promotion: Impacts on Body Composition and Physical Fitness in Young Chinese Children. BMC Pediatrics, 14, 118.

https://doi.org/10.1186/1471-2431-14-118 